JOURNAL OF ENGINEERING SCIENCES

ЖУРНАЛ ІНЖЕНЕРНИХ НАУК

ЖУРНАЛ ИНЖЕНЕРНЫХ НАУК

Web site: http://jes.sumdu.edu.ua

DOI: $10.21272 /$ jes.2017.4(2).g1

Volume 4, Issue 2 (2017)

UDC 504.054

\title{
Modeling of waterborne pollution of roadside soils
}

\author{
Plyatsuk L. D., Vaskina I. V. , Kozii I. S., Solianyk V. A., Vaskin R. A., Jakhnenko O. M.
}

Sumy State University, 2 Rymskogo-Korsakova St., 40007, Sumy, Ukraine

\author{
Article info: \\ Paper received: \\ The final version of the paper received: \\ Paper accepted online:
}

\author{
October 26, 2017 \\ November 25, 2017 \\ December 2, 2017
}

\author{
*Corresponding Author's Address: \\ irulik.vaskina@gmail.com
}

\begin{abstract}
Motor transport and road maintenance are the determining factors of environmental pollution in the roadside zone. The main acceptor of pollution in this case is the soil. In connection with the complexity of the application of instrumental control methods, it is perspective to carry out the monitoring of roadside territories on the basis of mathematical modeling. The objective of the study is to develop a model of vehicle emissions impact on roadside soils with washout from the road bed. As a physical model we will consider roadside underlying surface covered with a layer of raindrops. According to the physical model, pollutants are absorbed by rain drops when falling on the underlying surface. Movement of pollutants down the whole depth of soil profile is carried out under the action of filtering the contaminated liquid in the granular material of soil. Analytical dependencies have been obtained allowing to predict the roadside ecosystem pollution from exhaust emissions. Soil contamination with liquid effluents resulting from the dissolution of sulfur dioxide in atmospheric precipitation has been calculated.
\end{abstract}

Keywords: motor transport, exposure, pollutants, migration, soil profile, concentration, filtration, diffusion, sulfur dioxide.

\section{Introduction}

Motor transport and road maintenance are the determining factors of environmental pollution in the roadside zone, as they provide the environment with huge amounts of dust, soot, waste gases, oils, heavy metals and dozens of other toxicants. The threat of irreversible degradation of biosystems under the intensive influence of vehicles requires the level of their pollution to be forecasted and the adverse consequences to be prevented. It is perspective to carry out the monitoring of roadside territories on the basis of mathematical modelling. However, the adequacy of the model should prove to be true instrumentally and assume subsequent environmental monitoring with the employment of computer capabilities.

The objective of the study is to develop a model of vehicle emissions impact on roadside soils. Apart from the atmospheric pollution, washout from the road bed, that is, pollution through water also should be considered. This is the task of the given study.

\section{Methods}

The main criteria for the environmental quality of the roadside territories are concentrations of nitrogen dioxide, heavy hydrocarbons, carbon monoxide and sulphur dioxide, heavy metals, as well as the pollutants flux density falling on the underlying surface and moving into the ground with liquid rainwater [1]. The most unfavourable factor combination along motor ways emerges in places passing through inhabited areas, areas with large slopes, intersections at grade [2].

Roadside contamination monitoring is usually restricted to determining the concentrations of pollutants in the air, soil and plants [2]. Its implementation results from instrumental measurements of the main parameters included in the criteria for determining the quality of the ambient air and the biosphere. It should be noted that the instrumental method is very expensive and laborconsuming. The organization of soil monitoring provides for a comprehensive solution of the issues related to the determination of the actual pollution level, the forecast of potential contamination in the future, available and predictable consequences of this pollution. 
Models are built with certain assumptions according to the solution of the specific assignment. A detailed classification of such mathematical models is resulted in the monograph [3]. The most well-known implementations of such models are software products Amerod, Calpuff, ADMS-3, Caline3, OCD. The majority of the developments on the given subject are based on the diffusion equation of a pollutant in soil under the action of filtration and adsorption [4]. This approach is completely justified and logical.

\section{Results}

As a physical model we will consider roadside underlying surface covered with a layer of raindrops.

According to the physical model, pollutants are absorbed by rain drops when falling on the underlying surface. Let us calculate the initial concentration of pollutants in rainwater runoff, which is predetermined by their concentration in the air. The concentration in rain drops depends first of all on the absorption rate $\alpha, \mathrm{mg} /\left(\mathrm{s} \cdot \mathrm{m}^{3}\right)$, as well as water solubility of contaminants $R, \mathrm{mg} / \mathrm{l}$.

Let us admit that a raindrop falls with a uniform velocity $q, \mathrm{~m} / \mathrm{sec}$, from height $b$. Then, over the fall time $b / \mathrm{q}$ absorbs the following amount of gas:

$$
G=\alpha \cdot \frac{b}{q} \cdot V
$$

where $\mathrm{V}$ is droplet volume in which the pollutant concentration becomes equal to $\alpha \cdot b / q$.

At the same time, the limiting value of pollutant concentration in a raindrop is practically not achievable, since it is restricted by its solubility in water $R, \mathrm{mg} / \mathrm{l}$. According to [5] sulphur oxides have the highest solubility, while water solubility of nitrogen and carbon oxides is by an order lower. With increase in temperature, the water solubility of pollutants decreases except lead compounds, for which solubility rises with temperature increase.

For the initial pollutant concentration in water with reference to solubility, we obtain the following values:

$$
\begin{aligned}
& G_{\alpha}=\left\{\begin{array}{l}
\alpha \cdot \frac{b}{q} \cdot V, \quad \alpha \frac{b}{q}<\rho_{g} R \\
\rho_{g} R, \quad \alpha \frac{b}{q} \geq \rho_{g} R
\end{array}\right. \\
& C_{L}(\mathrm{t}, \mathrm{z})=\mathrm{C}_{0} \exp \left[-\left(\lambda \frac{v^{2}}{4 D}\right) \frac{t}{m}\right]+\exp \left(z \sqrt{\frac{\alpha}{D}}\right) \operatorname{erfc}\left(\frac{z+2 t \sqrt{\frac{\alpha}{D}}}{2 t \sqrt{\frac{D}{m}}}\right)-C_{0} \exp \left(-\frac{\lambda t}{m}\right) . \\
& \cdot\left\{\exp \left(-\frac{z v}{2 D}\right) \operatorname{erfc}\left(\frac{z-\frac{v t}{m}}{\sqrt{\frac{D t}{m}}}\right)+\frac{1}{2} \exp \left(\frac{\vartheta z}{2 D}\right) \cdot\left[C_{1} \cdot\left[\exp \left(-z \sqrt{\frac{\alpha}{D}}\right) \cdot \operatorname{erfc}\left(\frac{z-2 t \sqrt{\frac{\alpha}{D}}}{2 t \sqrt{\frac{D}{m}}}\right)+\exp \left(\frac{z v}{2 D}\right) \operatorname{erfc}\left(\frac{z-\frac{v t}{m}}{\sqrt{\frac{D t}{m}}}\right)\right]\right]\right\} \\
& L\left(C_{L}\right)=\int_{0}^{\infty} e^{-p t} C_{L}(t, z) d t=\tilde{C}(\mathrm{p}, \mathrm{z})
\end{aligned}
$$

where $\rho_{g}(\mathrm{mg} / \mathrm{ml})$ is the gas density under the following conditions: temperature $0{ }^{\circ} \mathrm{C}$, pressure $101325 \mathrm{kPa}$.

Movement of pollutants down the whole depth of soil profile is carried out under the action of filtering the contaminated liquid in the granular material of soil. We assume that the diffusion coefficient $\mathrm{D}$ in the direction perpendicular to fluid motion is equal to 0 .

With reference to the rate of filtration, the equation of pollutant motion in the water moving through the interstices of soil will be written as follows:

$$
m \frac{\partial C_{L}}{\partial t}=D \frac{\partial^{2} C_{L}}{\partial Z^{2}}-v \frac{\partial C_{L}}{\partial Z}+\lambda C_{L}
$$

where $\lambda$ - gas adsorption rate by the surface soil particles, expressed in fractions in the unit of time, $\sec ^{-1} ; \mathrm{m}-$ soil porosity:

$$
m=\frac{V_{1}}{V}
$$

where $V_{1}$ - pore volume; $V$ - total amount of porous centration of pollutants in the wet soil $C_{S}(\mathrm{mg} / \mathrm{kg})$, and in water in soil pores $C_{L}(\mathrm{mg} / \mathrm{l})$ :

$$
C_{S}=\frac{C_{L}}{\rho_{S}} m
$$

where $\rho_{S}-$ soil bulk density, $\mathrm{kg} / \mathrm{l}$.

One has to bear in mind that from the total concentration,in the form bound with hard soil frame there is a share of pollutants equal to the following integral

$$
\int_{0}^{t} \lambda C_{S} d \tau
$$

Considering $V, m, D, \lambda, C_{0}, C_{1}$ as constants, and having set the edge conditions (initial $C_{L}=C_{0}$ at $t=0, Z>0$, boundary $C_{L}=\mathrm{C}_{1}$ at $\left.x=0, t>0\right)$ let's apply the Laplace transformation to the equation (3):

By means of Laplace transforms with reference to numeric constants, characterizing the processes of filtration, diffusion and absorption and taking into account soil 
where $\alpha=\lambda+0.25 v^{2} / D$.

One of the main properties of soil is its porosity (duty factor) $-\sigma$, representing the ratio of the pore volume $V_{p}$ to the total volume of soil $V$ :

$$
\sigma=\frac{V_{p}}{V}
$$

The study of pollutant migration mechanism from literature sources [6] shows, that they move in the soil profile with gravitational water under the action of pressure difference.

Alongside with soil porosity, one should take into account the surface porosity $-m$, which is meant as the ratio of pores area $S_{p}$ to the entire sectional area $S$ :

$$
m=\frac{S_{p}}{S}
$$

Solution of the filtration rate equation shows that the average volume porosity $\sigma$ coincides with the average surface porosity $m$.

Filtration occurs under the action of pressure difference. For small pressure heads which are observed in the roadside soils, Darcy's law is used for filtration rate:

$$
v=-k \frac{d h}{d l}
$$

where $h=z+p / \gamma-$ hydrostatic head; $k-$ filtration coefficient depending on temperature.

Darcy's law is true at Reynolds number $R e=\vartheta d / V$ less than $3-10$, that is at $\vartheta \mathrm{d} \leq 0.070-0.075$, because of $\vartheta=0.018 \mathrm{sm}^{2} / \mathrm{s}$.

According to rainwater runoff transport mechanism, water elevation through capillaries occurs under the action of surface tension forces $2 \sigma / \gamma_{g}$ to the height $h_{k}$ :

$$
P=P_{a}-\gamma h_{k}
$$

The rate of filtration depends on the intensive intake of rainwater on the soil surface. To calculate filtration, the value of $q_{20}$ (20 minutes of atmospheric precipitation for our locality with one-year single exceeding) will be taken as rain intensity. At the same time, the formation of surface runoff with a flow rate should be taken into account, and water will penetrate into the soil with the intensity $q$ equal to

$$
q=q_{20} \frac{q_{f}}{F}
$$

where $F$ - runoff area.

By the time $t$, there will be accumulated a rainwater layer $q_{t}$ thick, part of it $H$ will be located above the ground surface, while the other part will penetrate into the ground to the percolation depth $y(t)$. At each moment of time the equality is implemented:

$$
q_{t}=H(t)+m \cdot y(t)
$$

To obtain an equation characterizing water layer extension into the ground, let's direct the $O Z$ axis downward, and the origin of coordinates will be counted from the ground surface. Then the filtration equation can be rewritten as:

$$
\vartheta=-k \frac{\partial h}{\partial z}
$$

where $h=p / \gamma-z$.

It results from the continuity equation that the filtration rate depends only on the time $t$ and does not depend on $z$, therefore, in view of the fact that the head $h$ is a linear function of $z$. When $z=y$, pressure $P$ is determined by (11). Then

$$
a(t)=\frac{\partial h}{\partial z}=-\frac{H+h_{k}+y-\frac{P_{a}}{\gamma}}{y}
$$

We have an obvious ratio for the filtration rate:

$$
\vartheta=m \frac{d y}{d t}
$$

Comparing (12) and (13), we obtain the equation in order to determine the percolation depth $y(t)$ :

$$
m \frac{d y}{d t}=k \frac{q t+y(1-m)+h_{k}-\frac{P_{a}}{\gamma}}{y}
$$

which gets integrated provided that $y=0$ at $t=0$.

The above ratios are true only at $t<20 \mathrm{~min}$., that is during rain.

Once the rain is over (i. e., 20 minutes later), instead of proportion (13) into the equation (15), it is necessary to put

$$
H-H_{20}+m\left(y_{20}-y\right)
$$

Here $y_{20}, H_{20}$ - values of $h(t)$ and $H(t)$ at $t=20 \mathrm{~min}$.

The ratio(18) expresses the mass balance. In this respect the equation (15) takes the following form:

$$
m \frac{d y}{d t}=k \frac{H_{20}+m \cdot y_{20}+y(1-m)+h_{k}-\frac{P_{a}}{\gamma}}{y}
$$

provided that $y_{20}=y$ at $t=t_{R}$, where $t_{R}=20 \mathrm{~min}-$ the duration of rain.

The solution of (19) is the integral

$k\left(t-t_{R}\right)=\frac{m}{(1-m)^{2}}\left[(1-m) \cdot\left(y-y_{20}\right)-n \ln \left|\frac{n+y(1-m)}{n+y_{20}(1-m)}\right|\right]$ (20)

where

$$
n=H_{20}+m \cdot y_{20}+h_{k}-\frac{P_{a}}{\gamma}
$$


The solution of (20) is true up to the time $t_{L}$, when $H=0$, i. e. water is not available above the ground. With reference to (18) $y=y_{L}$ will acquire a value

$$
y_{L}=y_{20}+\frac{H_{20}}{m}
$$

Inserting(22) into the solution(20), we will obtain:

$t_{L}=t_{R}+\frac{m}{k(1-m)^{2}}\left[(1-m) \frac{H_{20}}{m}-n \ln \left|\frac{n+\left(y_{20}+\frac{H_{20}}{m}\right)(1-m)}{n+y_{20}(1-m)}\right|\right]$

At a time interval $t_{L}<t<t_{R}$, the filtration rate value $\vartheta$ is considered equal to the mean value of $m \cdot d y / d t$, which can be represented by way of increment of function in the form

$$
\vartheta=m \frac{y_{L}-y_{20}}{t_{L}-t_{R}}
$$

After point of time $t_{L}$, the equation describing the further pollutant invasion into soil remains the same, but the solution must take into account the mobility of the upper edge for soil wetting.

\section{Discussion}

To verify the model adequacy, we calculated the concentrations of $C_{L}$ by the equation (8) for the following initial data:

- the rain intensity was assumed to be $0.0001 \mathrm{~m} / \mathrm{sec}=$ $=0.36 \mathrm{~m}^{3} / \mathrm{h}$ (low intensity rain);

- the content of $\mathrm{SO}_{2}$ in rainwater is taken equal to the limiting solubility of sulfur dioxide at ambient temperature of $15^{\circ} \mathrm{C}: R=47.3 \mathrm{ml} / 1 ; C_{l}^{S O 2}=\rho-R=$ $=2.9266-27347.3 / 288=131.2(\mathrm{mg} / \mathrm{l})=C_{1}(z=0$, $t>0)$;

- soil-clay loam: for porosity $m=0.35$ we have $k=10^{-6} \mathrm{~m} / \mathrm{sec}=0.003 \mathrm{~m} / \mathrm{hr}[4]$;

- capillary lift height $h_{k}=2.25 \mathrm{~m}$; mass transfer coefficient $\lambda=1.6 R e^{0.54} D / d^{2}=0.04 \mathrm{~m} / \mathrm{sec}$ at $d=0.002 \mathrm{~m}$, $V=10^{-6} \mathrm{~m}^{2} / \mathrm{s}, W=1 \mathrm{~m} / \mathrm{s}, D=2 \cdot 10^{-9} \mathrm{~m}^{2} / \mathrm{s}$ - diffusivity of gases in water [7].
While substituting the design data into (7), we obtain the values $2 C_{L} / \mathrm{C}_{1}$ and $C_{L}$ for two variants. The results of the calculation are given in Table1.

Table 1 - The calculation of $\mathrm{SO}_{2}$ concentrations in rain drops with rain intensity of $R=0.36 \mathrm{~m}^{3} / \mathrm{hr}$

\begin{tabular}{|c|c|c|c|c|}
\hline \multirow{2}{*}{ Time, s } & \multicolumn{2}{|c|}{ Coordinate $\mathrm{Z}=0.01 \mathrm{~m}$} & \multicolumn{2}{c|}{ Coordinate $\mathrm{Z}=0.02 \mathrm{~m}$} \\
\cline { 2 - 5 } & $2 C_{L} / C$ & $C_{L}, \mathrm{ml} / 1$ & $2 C_{L} / C$ & $C_{L}, \mathrm{ml} / 1$ \\
\hline 10 & 0.0712 & 4.67 & 0.000271 & 0.0178 \\
\hline 15 & 0.184 & 12.07 & 0.0050 & 0.328 \\
\hline 20 & 0.25 & 16.4 & 0.00563 & 0.369 \\
\hline 25 & 0.177 & 11.61 & 0.0164 & 1.08 \\
\hline 30 & 0.1494 & 9.80 & 0.0264 & 1.732 \\
\hline 60 & 0.147 & 9.64 & 0.0408 & 2.676 \\
\hline 600 & 0.142 & 9.32 & 0.0221 & 1.45 \\
\hline
\end{tabular}

Studies have shown that with the change in rain time, the concentration of sulfur dioxide in puddle raindrops, located at the distance of $5 \mathrm{~m}$ from the highway roadbed edge, increases to maximum, after that the concentration decreases. At the same time, the concentration of sulfur dioxide within the depth of the soil profile decreases by almost an order of magnitude changing $Z$ in a range from 1 to $2 \mathrm{~cm}$. It should be noted that within 20-30 seconds after rain starts, the concentration in the puddle on the surface reaches $16 \mathrm{mg} / \mathrm{l}$.

\section{Conclusions}

Within the undertaken study, there has been developed a mathematical model for pollutants solubility in liquid rainfall run-off. Analytical dependencies have been obtained allowing to predict the roadside ecosystem pollution from exhaust emissions. Soil contamination with liquid effluents resulting from the dissolution of sulphur dioxide in atmospheric precipitation has been calculated. Moreover, the strong side of the model is its relative easy for programming in Mathematics application packages (e. g. MATLAB, Maple). 


\section{References}

1. Vnukova, N. V., \& Zhelnovach, G. M. (2011). Vybir ekologichnoznachymyh parametriv avtotransportnyh system dlya ocinky ekologichnoyi nebezpeky prydorozhnogo prostoru. [Selection of environmentally significant parameters of motor transport systems for assessing the ecological danger of roadside space]. Ecological safety, Vol. 2 (12), 119-123 http://www.kdu.edu.ua/ EKB_jurnal/2011_2(12) [in Ukrainian].

2. Lukanin, V. N., Buslaev, A. P., Trofymenko, Y. V., \& Yashyna, M. V. (2001). Avtotransportnye potoki i okruzhayushhaya sreda [Road traffic and the environment]. Moscow, Russia [in Russian].

3. Babkov, V. S., \& Tkachenko, T. J. (2011). Analiz matematicheskih modeley rasprostraneniya primesey ot tochechnyh istochnikov [Analysis of mathematical models of the spread of contaminants from point sources]. Donetsk, Ukraine [in Russian].

4. Polubarynova-Kochyna, P. Ya. (1977). Teoriya dvizheniya gruntovykh vod [Theory of groundwater movement]. Moscow, Russia [in Russian].

5. Nahaev, Z. N. (2003). Tehnogennoe vozdejstviye avtomobil'nykh dorog na ekosystemy prydorozhnoj polosy [Technogenic impact of motor roads on the roadside system]. Proceedings of the Forest Engineering Department PetrSU. Petrozavodsk, Russia, pp. 1-3 [in Russian].

6. Yurchenko, V. A., \& Mykhajlova, L. S. (2012). Osobennosti tekhnogennogo zagryazneniya pridorozhnogo prostranstva nefteproduktami [Features of technogenic contamination of roadside space by oil products]. Scientific Herald of Construction, Vol. 69, 404-407 [in Russian].

7. Fylyppov, V. V. (1990). Ekologicheskiye raschoty pri proektirovanii dorog [Environmental calculations for road design].Car roads, Vol. 5, 20-21 [in Russian]. 